\title{
Parametric Study of Defect Detection in Pipes with Bend Using Guided Ultrasonic Waves
}

\author{
Jin Jack Tan ${ }^{1}$, Xin Wang ${ }^{1 a}$, Ningqun Guo ${ }^{1}$ and Jee Hou $\mathrm{Ho}^{2}$ \\ ${ }^{1}$ School of Engineering, Monash University Malaysia, Jalan Lagoon Selatan, 47500 Selangor, Malaysia \\ 2 Department of Mechanical, Materials and Manufacturing Engineering, University of Nottingham Malaysia Campus, Jalan Broga, 43500 \\ Semenyih, Malaysia
}

\begin{abstract}
The propagation behaviour of guided ultrasonic waves in a steel pipe with welded bend is studied by finite element simulation. The effectiveness of the longitudinal $\mathrm{L}(0,2)$ and torsional $\mathrm{T}(0,1)$ guided waves in detecting circumferential cut near the weld is investigated. In order to identify the presence of the defect, the reflection strength due to the cut is studied. The geometry of the weld is constructed based on common V-bevel butt joints and the anisotropy of the $316 \mathrm{~L}$ stainless steel weld is included to correctly predict the scattering of ultrasonic waves. The finite element model is built to allow high accuracy. Detection of small circumferential cut (up to $60^{\circ}$ circumferential extent) can be achieved with longitudinal $\mathrm{L}(0,2)$ mode. Detection of moderate to large circumferential cut can be achieved by torsional $\mathrm{T}(0,1)$ or longitudinal $\mathrm{L}(0,2)$ modes, with $\mathrm{T}(0,1)$ mode preferred due to its less mode conversion to higher order modes.
\end{abstract}

\section{Introduction}

Ultrasonic guided wave testing is an attractive nondestructive testing (NDT) technique as it allows rapid and long range inspection from a single location. It also allows inspection of otherwise inaccessible regions of structure. Compared to conventional bulk waves, excited ultrasonic guided wave propagates along a waveguide like plates or pipes and has continual interaction with the boundaries of the waveguide. Therefore, the wave is confined and subsequently propagated over a long distance. Upon meeting a defect or anomaly, guided wave interacts with the defect which results in a reflected wave. The reflected wave is detected by the excitation transducer where the time difference between the initial and reflected wave can be used to locate the anomaly given known velocities of the wave. Thus guided wave is very attractive for industries involving large and complex pipelines structures.

Guided wave was applied to detect various kinds of defects, including circumferential notches [1], sludge [2], axisymmetric defects with varying depth [3], multiple circular holes [4], defect beyond weld [5], complex defect profiles [6] and corrosion defects [7]. More complex cases like pipes with fluid loading [8-10] and coated pipes [11-13] are also pursued by various authors.

Pipe with bend, on the other hand, receives relatively less attentions due to several difficulties. Defect detection based on the reflection signals scattered by the defects can be interfered by or confused with the reflection signals due to welds, which is commonly used to join pipe bend to straight pipes. In addition to that, mode conversion and dispersion of guided wave occur as it propagates through bend and deteriorates the reflection signals. Several methods have been used to derive the dispersion relations and to describe the propagation and scattering behaviour across the bend, including semianalytical finite element formulation [14], analytical [15], numerical [16-17] and experimental approach [18]. There are also several works on detecting defect in a pipe with bend with defect at the bend [19-21] and beyond the bend [22-23].

In this paper, we investigate the guided wave detection ability of defects that exist near to weld and bend using finite element simulation. In the study, two steel pipes are joined by a 90-degree bend of same material via V-bevel butt joint welds. A thin circumferential cut is artificially introduced near to the weld to simulate a crack. The circumferential extent of the cut is varied and its effect to the reflection coefficient of the guided wave is monitored. Reflection coefficient is defined as the ratio of the amplitude of the reflection wave due to the defect to the amplitude of the reflection wave due to the end of the pipe in a defect-free pipe.

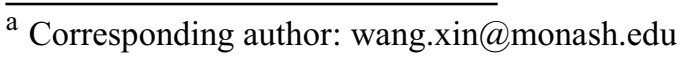




\section{Finite element simulation}

In the simulation, two 2-inch schedule 40 steel pipes (external diameter of $60 \mathrm{~mm}$ and wall thickness of $4 \mathrm{~mm}$ ) with length of $0.3 \mathrm{~m}$ are joined together with a bend by welds as shown in Figure 1. The bend has same diameter and wall thickness and has a bend radius of $76 \mathrm{~mm}$. The welds are V-bevel butt joint weld and have the geometry as shown in Figure 2(b) and both welds are identical. Root opening and root height is $0.8 \mathrm{~mm}$ and included angle is $60^{\circ}$. The width of the welds at the outer surface is $4 \mathrm{~mm}$. The welds are $316 \mathrm{~L}$ industrial austenitic stainless steel welds and their anisotropy is described accordingly [35]. Thin circumferential cut $\mathrm{E}$ is introduced $5 \mathrm{~mm}$ after the weld $\mathrm{D}$ and is centered at the extrados of the pipe as shown in Figure 2(a).

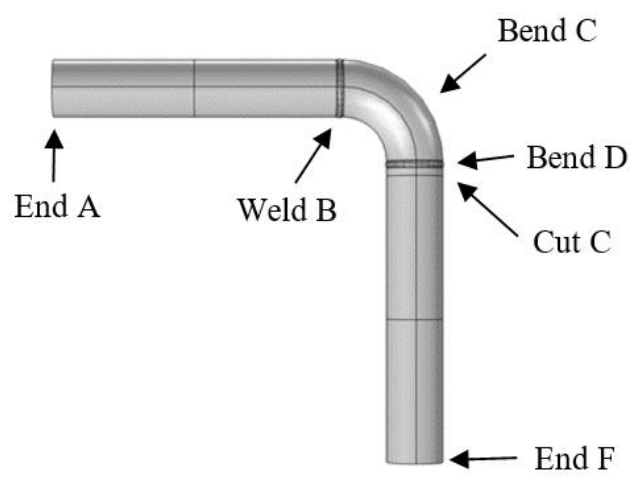

Figure 1. Geometrical setup of the finite element simulation in COMSOL.

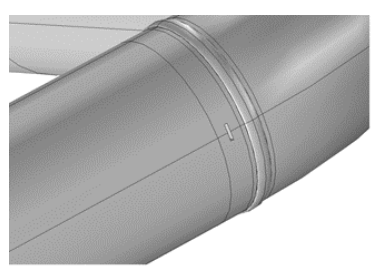

(a)

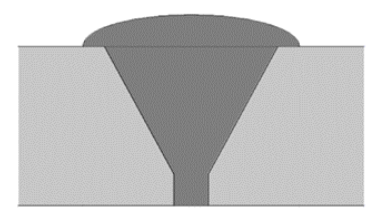

(b)
Figure 2. (a) A closer view of the weld D and cut E. The cut shown has a circumferential extent of $10^{\circ}$. (b) The geometry of the weld used in the simulation. The geometry is used for both weld $\mathrm{B}$ and weld $\mathrm{D}$.

Guided wave is excited at the outer edge of the end $\mathrm{A}$ and travels across weld $\mathrm{B}$, bend $\mathrm{C}$, weld $\mathrm{D}$ and meets defect $\mathrm{E}$ before reflecting from end $\mathrm{F}$. The monitoring probes are at end A, coinciding the excitation points. This is to reflect the actual guided wave setup where the transducers ring usually acts as both the excitation source and receiving sensor. Excitation of the torsional $\mathrm{T}(0,1)$ and longitudinal $\mathrm{L}(0,2)$ with different orientation is shown in Figure 3. The excitation pulse is a 5-cycle Hanning window at $70 \mathrm{kHz}$. Each mode is excited across the whole circumference of end $A$ with no delays between each other elements. $70 \mathrm{kHz}$ is chosen as the investigated modes are fairly non-dispersive at that frequency as shown from the group velocity curves in Figure 4.

Table 1. The Young's modulus, Poisson ratio and density of the materials used.

\begin{tabular}{|l|l|l|l|}
\hline Material & $\begin{array}{l}\text { Young's } \\
\text { Modulus } \\
(\mathbf{G P a})\end{array}$ & $\begin{array}{l}\text { Poisson } \\
\text { Ratio }\end{array}$ & $\begin{array}{l}\text { Density } \\
\mathbf{( k g m}^{-3} \mathbf{)}\end{array}$ \\
\hline Steel & 200 & 0.33 & 7850 \\
\hline $316 \mathrm{~L}$ & 200 & 0.3 & 8000 \\
\hline
\end{tabular}

$[C]=10^{9}\left[\begin{array}{cccccc}194 & 139 & 139 & 0 & 0 & 0 \\ 139 & 233 & 100 & 0 & 0 & 0 \\ 139 & 100 & 233 & 0 & 0 & 0 \\ 0 & 0 & 0 & 65 & 0 & 0 \\ 0 & 0 & 0 & 0 & 106 & 0 \\ 0 & 0 & 0 & 0 & 0 & 106\end{array}\right] \mathrm{Pa}$

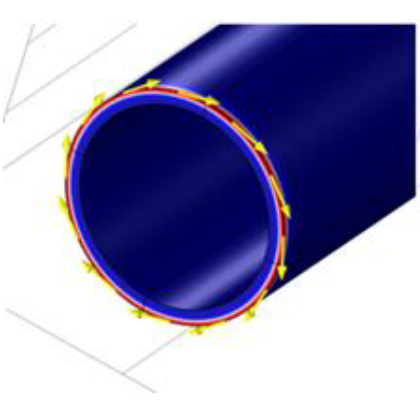

(a)

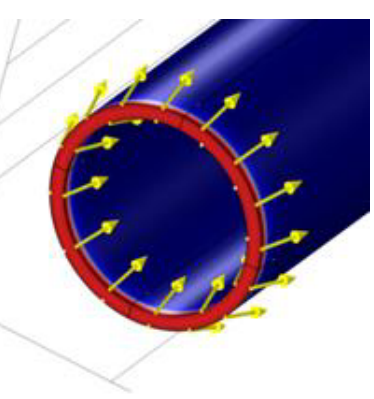

(b)
Figure 3. Excitation of the (a) torsional $\mathrm{T}(0,1)$, (b) longitudinal $\mathrm{L}(0,2)$ with different orientation. The yellow arrows indicate the direction while the colour map indicates strength.

Grid independency study is conducted and to obtain high accuracy study, the time steps are discretized such that there are 16 nodes in one period of the investigated frequency (i.e. $70 \mathrm{kHz}$ ) and the spatial element sizes are discretized such that there are at least 16 nodes in one wavelength corresponding to the interested modes. This results in a time step of $9.52 \mathrm{e}-7 \mathrm{~s}$ and an element size of $3 \mathrm{~mm}$. The wall thickness is also discretized such that there are two elements across the thickness which allows representation of mode shape up to second order guided wave modes.

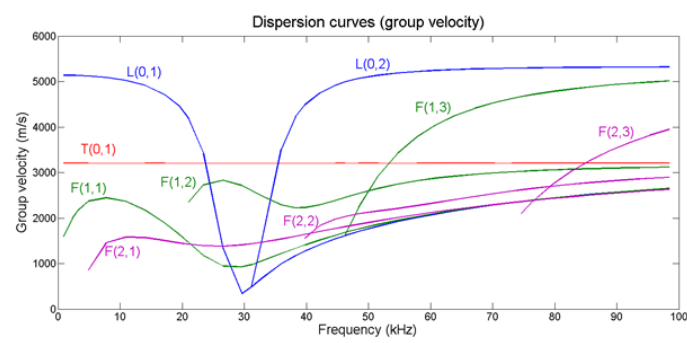

Figure 4. Group velocity dispersion curve of a steel pipe with $30 \mathrm{~mm}$ external radius and $4 \mathrm{~mm}$ pipe wall thickness, showing up to second order modes. 


\section{Defect detection ability}

The displacement-time response for $\mathrm{T}(0,1)$ guided wave mode at the excitation end for a defect-free pipe is as shown in Fi5. Few wave packets can be identified. The first wave packet is the incident wave packet. The second and third waves, at $220 \mu$ s and $340 \mu$ s respectively, are the reflection due to the two welds of the bend. A small wave packet at around $450 \mu$ s is likely a weak higher order reflection from one of the welds while the large wave from $520 \mu \mathrm{s}$ is the reflection from the end of the pipe. The displacement-time response for $\mathrm{L}(0,2)$ mode is similar with just a different travelling time due to its higher group velocity. It is thus omitted for brevity.

The displacement-time response for $\mathrm{T}(0,1)$ wave mode at the excitation end for a pipe with a circumferential notch that extends $30^{\circ}$ circumferentially is as shown in Fig6. As can be seen, the response looks almost identical to the one without defect. This is because even though there is reflection due to the defect, it is superposed onto the reflection of second weld, consequently making it impossible to detect. Reflection coefficients of the pipe when excited with $\mathrm{T}(0,1)$ for various circumferential extents are plotted in Fig7. Defect extent that is less than or at $30^{\circ}$ circumferentially is virtually impossible to be detected by $\mathrm{T}(0,1)$ mode given its similar reflection coefficient with a defect-free pipe. Monitoring reflection of higher order mode is also not suitable, as even though it has a small increase, the difference in reflection is too small to call for a defect.

Reflection coefficients of the pipe when excited with $\mathrm{L}(0,2)$ for various circumferential extents are shown in Figure 8 . One biggest difference between the response of $\mathrm{L}(0,2)$ and $\mathrm{T}(0,1)$ mode is that $\mathrm{L}(0,2)$ mode is able to differentiate a defect-free pipe from a pipe that contains a small defect based on reflection of the fundamental mode. Consequently, if the reflection without defect is known, defect with $10^{\circ}$ circumferential extent can be detected by observing the fundamental zero-th order reflection. A second order mode, likely to be $F(2,2)$ based on its travelling time, is also present strongly for pipes containing small defects. Both of these modes can be monitored together to improve the confidence to call for a defect. For bigger defect from $30^{\circ}$ onwards, in addition to the dominant fundamental zero-th order reflection, first order mode, likely a $F(1,3)$ based on travelling time, can be monitored as well for defect detection. First order mode reflection can be used to characterize the size of the defect for moderately larger cut from $120^{\circ}$ onwards.

Two interesting remarks can be made from studying the reflection coefficients of $\mathrm{T}(0,1)$ and $\mathrm{L}(0,2)$ modes in a pipe with welded bend. Firstly, being a non-dispersive mode, $\mathrm{T}(0,1)$ mode has much lesser mode conversion to higher order modes than $\mathrm{L}(0,2)$ modes. While the higher order modes can serve as additional information to detect defects, they can also affect and distort the signals significantly. Interpretation can be much more challenging for a more complex case, e.g. a pipe with more bends, welds and defects, pipe under fluid loading etc. On the other hand, the low mode conversion of $\mathrm{T}(0,1)$, despite propagating through a bend, makes it a viable candidate to detect a moderately sized defect and potentially on more challenging and complex cases.

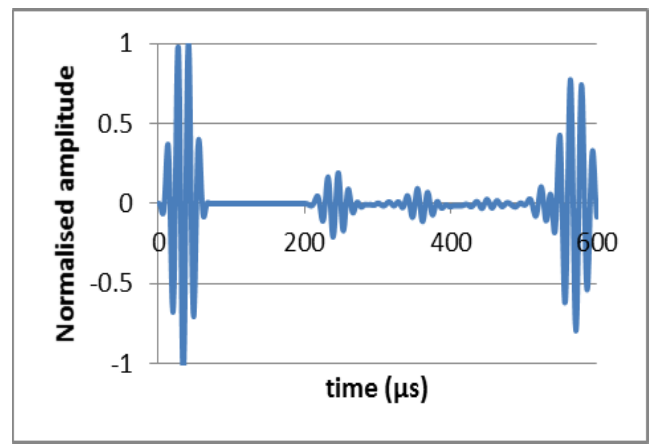

Figure 5. Displacement-time response for $\mathrm{T}(0,1)$ of a pipe with welded bend without defect.

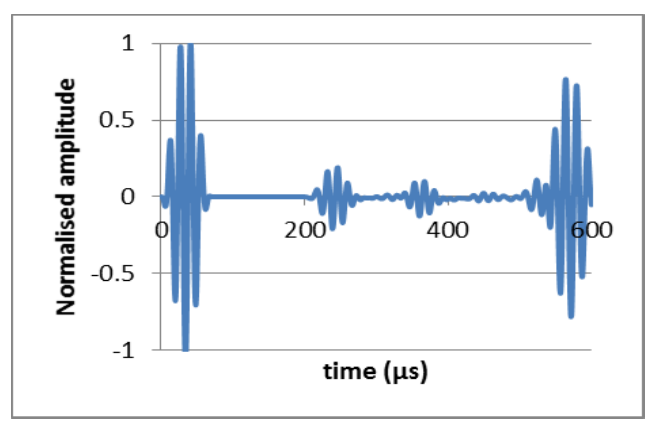

Figure 6. Displacement-time response for $\mathrm{T}(0,1)$ of a pipe with welded bend with a circumferential notch that extends $30^{\circ}$ circumferentially.

Secondly, when comparing the reflection of $\mathrm{L}(0,2)$ mode in a pipe with bend to the reflection in a straight pipe (as can be seen in Fig9), it can be inferred that mode conversion occurs when propagating across and back the bend. While first order mode has its minimum when there is no defect in the case of pipe with bend, its reflection is at its maximum when there is a full circumferential notch. This is in contrast to the result in a straight pipe where first order mode is minimal when there is a full circumferential notch. This indicates that the existence of bend has resulted in the development of a stronger first order mode when the guided wave interacts with the defect.

The existence of second order mode even in a defect free pipe with bend also indicates that mode conversion to second order mode occurs when propagating through and back the bend. However, similar to the reflection of a straight pipe, it exhibits two peaks, first at around $90^{\circ}$ and second at around $240^{\circ}$. The first peak coincides with the peak of a straight pipe while the second peak of a straight pipe occurs around $270^{\circ}$. This indicates that in addition to the second order mode developed due to the bend, it is also developed in a predictable fashion when interacting with the defect, i.e. peak at around $90^{\circ}$ and $270^{\circ}$. 


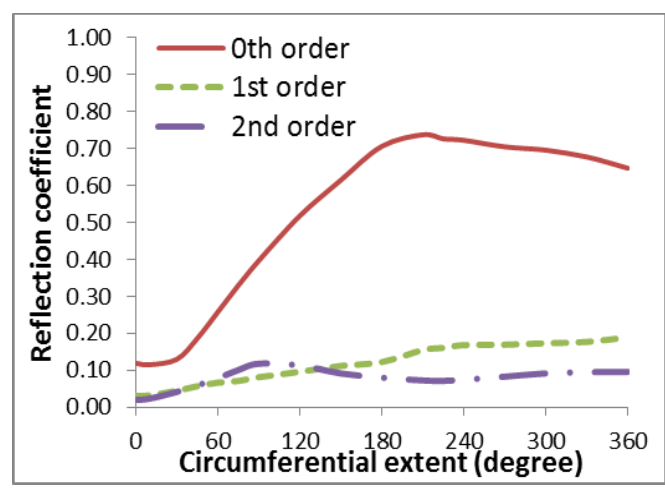

Figure 7. Reflection coefficient for $\mathrm{T}(0,1)$ mode against notch of variable circumferential extent.

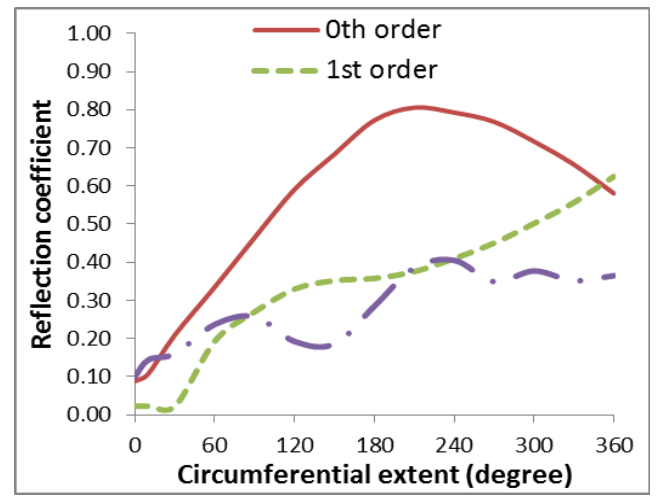

Figure 8. Reflection coefficient for $\mathrm{L}(0,2)$ mode against notch of variable circumferential extent.

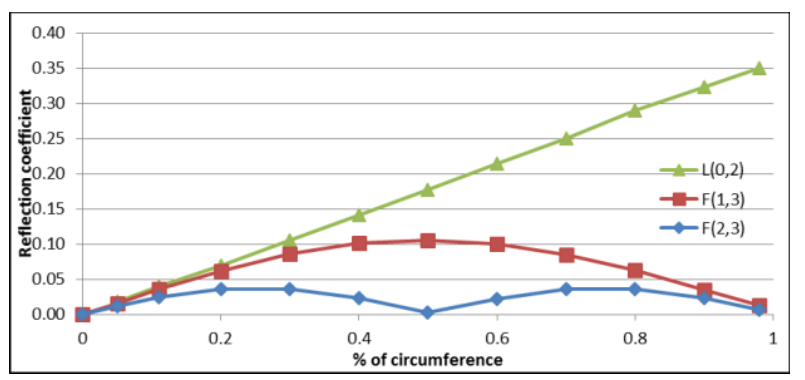

Figure 9. Reflection coefficient against percentage of circumference extent of notches at $50 \%$ depth extent for straight pipe.

\section{Conclusion}

The propagation behaviour of guided ultrasonic waves in a steel pipe with welded bend is studied by finite element simulation. The effectiveness of the longitudinal $\mathrm{L}(0,2)$ and torsional $\mathrm{T}(0,1)$ guided waves in detecting circumferential cut near the weld is investigated. Detection of small circumferential cut (up to $60^{\circ}$ circumferential extent) can be achieved with longitudinal $\mathrm{L}(0,2)$ mode. Detection of moderate to large circumferential cut can be achieved by torsional $\mathrm{T}(0,1)$ or longitudinal $\mathrm{L}(0,2)$ modes, with $\mathrm{T}(0,1)$ mode preferred due to its less mode conversion to higher order modes. Reflection of a defect-free pipe and a pipe with a small $10^{\circ}$ circumferential defect can be detected by $\mathrm{L}(0,2)$ mode. However, strong mode conversion of the $\mathrm{L}(0,2)$ mode may affect its performance on more complex cases. On the other hand, the non-dispersive $\mathrm{T}(0,1)$ mode cannot detect defect that extends less than or at $30^{\circ}$ circumferentially.

\section{References}

1. Demma, A, Cawley, P and Lowe, M. The reflection of the fundamental torsional mode from cracks and notches in pipes. Journal of Acoustical Society of America, 2 (2003).

2. Ma, J, Lowe, M and Simonetti, F. Feasibility study of sludge and blockage detection inside pipes using guided torsional waves. Measurement Science and Technology, 14 (2007).

3. Carandente, R, Ma, J and Cawley, P. The scattering of the fundamental torsional mode from axisymmetric defects with varying depth profile in pipes. Journal of Acoustical Society of America, 127 (2001).

4. Cawley, P and Lovstad, A. The reflection of fundamental torsional guided wave from multiple circular holes in pipes. NDT\&E International, 46 (2011).

5. Zhang, L, Luo, W and Rose, J. Ultrasonic guided wave focusing beyond welds in a pipeline. Review of Quantitative Nondestructive Evaluation, 25 (2006).

6. Moreau, L, Velichko, A and Wilcox, P. Accurate finite element modeling of guided wave scattering from irregular defects. NDT\&E International, 46 (2012).

7. Carandente, $\mathrm{R}$ and Cawley, $\mathrm{P}$. The effect of complex defect profiles on the reflection of the fundamental torsional mode in pipes. NDT\&E International, 46 (2012).

8. Aristegui, C, Lowe, MJ and Cawley, P. Guided waves in fluid-filled pipes surrounded by different fluids. Ultrasonic, 39 (2001).

9. Baik, K, Jiang, J and Leighton, T. Acoustic attenuation, phase and group velocities in liquidfilled pipes: Theory, experiment, and examples of water and mercury. Journal of Acoustical Society of America, 128 (2010).

10. Jin, S, et al. Study on ultrasonic guided waves in fluid-filled pipes surrounded by water. Calgary (2006).

11. Kwun, $\mathrm{H}$, et al. Torsional guided-wave attenuation in coal-tar-enamel-coated, buried piping. NDT\&E International, 37 (2004). 
12. Ma, J, Simonetti, F and Lowe, MJ. Scattering of the fundamental torsional mode by an axisymmetric layer inside a pipe. Journal of Acoustical Society of America, 120 (2006).

13. Kirby, R, Zahari, $Z$ and Mudge, $P$. On the scattering of longitudinal elastic waves from axisymmetric defects in coated pipes. Journal of Sound and Vibration, 332 (2012).

14. Hayashi, T., Kawashima, K., Sun, Z., and Rose, J.L., Guided wave propagation mechanics across a pipe elbow, Journal of Pressure Vessel Technology, 127 (2005).

15. Sanderson, R., Billson, D., Hutchins, D., and Mudge, $\mathrm{P}$., The investigation of guided wave propagation around a pipe bend using an analytical modelling approach, J. Acoust. Soc. Am., 133 (2013).

16. Verma, B., Balasubramaniam, K., and Rajagopal, P., Studies on the influence of axial bends on ultrasonic guided waves in hollow cylidners (pipes), AIP Conf. Proc., 1511 (2013).

17. Demma, A., Cawley, P., and Pavlakovic, B., The effect of bends on the propagation of guided waves in pipes, Journal of Pressure Vessel Technology, 127 (2005).

18. Yoshida, H., Nishino, K., Cho, H., and Takemoto, M."Propagation phenomena of wideband guided waves in a bended pipe", Ultrasonics, 44 (2006).

19. Predoi, M., and Petre, C., Guided waves scattering by discontinuities near pipe bends, J. Acoust. Soc. Am., 133 (2013).

20. Yamamoto, T., Furukawa, T., and Nishino, H., Efficient defect detections of elbow pipes using propagation characteristics of guided waves, AIP Conf. Proc., 1581 (2014)

21. Miki, M., Nagashima, Y., Endou, M., Kodaira, K., Koike, M., and Odakura, M., Evaluation for defect detection over bending zone in piping by guided wave, AIP Conf. Proc., 1211 (2010).

22. Rose, J.L., Zhang, L., Avioli, M., and Mudge, P., A natural focusing low frequency guided wave experiment for the detection of defects beyond elbows, Journal of Pressure Vessel Technology, 127 (2005).

23. L Zhang, W Luo and J Rose, Ultrasonic guided wave focusing beyond welds in a pipeline, Review of Quantitative Nondestructive Evaluation, 25 (2006). 